\title{
Three novel $\alpha$-L-iduronidase mutations in 10 unrelated Chinese mucopolysaccharidosis type I families
}

\author{
Luning Sun ${ }^{1}$, Chunyi $\mathrm{Li}^{2}$, Xiaoyu Song ${ }^{1}$, Ningning Zheng ${ }^{1}$, Haipeng Zhang ${ }^{1}$ and Guizhang Dong ${ }^{3}$ \\ ${ }^{1}$ Department of Pathophysiology, College of Basic Medical Science, China Medical University, \\ Shenyang, Liaoning Province, China. \\ ${ }^{2}$ Department of Genetics, College of Basic Medical Science, China Medical University, Shenyang, \\ Liaoning Province, China. \\ ${ }^{3}$ Department of Pediatrics, 1 st Hospital of China Medical University, Shenyang, Liaoning Province, China.
}

\begin{abstract}
Mucopolysaccharidosis type I (MPS I) arises from a deficiency in the $\alpha$-L-iduronidase (IDUA) enzyme. Although the clinical spectrum in MPS I patients is continuous, it was possible to recognize 3 phenotypes reflecting the severity of symptoms, viz., the Hurler, Scheie and Hurler/Scheie syndromes. In this study, 10 unrelated Chinese MPS I families (nine Hurler and one Hurler/Scheie) were investigated, and 16 mutant alleles were identified. Three novel mutations in IDUA genes, one missense p.R363H (c.1088G > A) and two splice-site mutations (c.1190-1G > A and c.792+1G > $\mathrm{T}$ ), were found. Notably, $45 \%$ (nine out of 20) and 30\% (six out of 20) of the mutant alleles in the 10 families studied were c.1190-1G > A and c.792+1G > T, respectively. The novel missense mutation p.R363H was transiently expressed in $\mathrm{CHO}$ cells, and showed retention of $2.3 \%$ IDUA activity. Neither p.W402X nor p.Q70X associated with the Hurler phenotype, or even p.R89Q associated with the Scheie phenotype, was found in this group. Finally, it was noted that the Chinese MPS I patients proved to be characterized with a unique set of IDUA gene mutations, not only entirely different from those encountered among Europeans and Americans, but also apparently not even the same as those found in other Asian countries.
\end{abstract}

Key words: mucopolysaccharidosis type I, $\alpha$-L-iduronidase, mutation, polymorphism.

Received: May 19, 2010; Accepted: December 1, 2010.

Mucopolysaccharidosis type I (MPS I, McKusick 252800 ) is an autosomal recessive disease, caused by a deficiency in the lysosomal enzyme $\alpha$-L-iduronidase (IDUA, E.C. 3.2.1.76). This leads to the accumulation of partially degraded mucopolysaccharides, thereby giving rise to certain clinical conditions, expressed notably by the Hurler (IH), Scheie (IS) and Hurler/Scheie (IH/S) syndromes (Hopwood and Morris, 1990). The incidence rate of MPSIH is $1 / 100,000$ to $1 / 150,000$, thus making it, not only the most common among all the forms of MPS, but also the main one in Chinese MPS I patients, as a whole. IH is the most severe, with symptoms developing during the first year of life, as severe mental retardation, skeletal deformities, hepatosplenomegaly and corneal clouding. IS, on the other hand, besides developing at a later period in life, manifests as aortic valve disease, stiff joints, corneal clouding and mild visceral organic problems, albeit no mental retardation. IH/S patients present most of the skeletal problems

Correspondence to Luning Sun. Department of Pathophysiology, College of Basic Medical Science, China Medical University, 92 Beier Road, 110001 Shenyang, Liaoning Province, China. E-mail: In.In.sun@gmail.com, Insun@ mail.cmu.edu.cn. associated with $\mathrm{IH}$, but with symptoms developing during the early to mid teens, associated with relatively little mental retardation (Schuchman and Desnick, 1988). It has been proposed that the variable severity of symptoms is an outcome of the different types of pathogenic mutations in the gene itself. Consequently, molecular biological analysis of MPS I exerts an important role in diagnosis. To date, more than 100 pathogenic mutations have been found in the IDUA gene (Human Gene Mutation Database, 2010-0301 ), and the higher prevalence of several mutations in certain geographic locations, such as p.W402X and p.Q70X among Caucasian patients (Bunge et al., 1994), has been demonstrated. Identification of the specific mutations in affected patients is useful both for prenatal diagnosis, as well as genotype-phenotype correlations, although the mutant type in Chinese mainland MPS-I patients is still unclear. Herein are described the results of mutation analysis of pathogenic mutations of the IDUA gene in a group of 10 Han Chinese MPS-I families, with a view to identifying the major mutations specific to China.

The group of 10 MPS I families under study included nine Hurler and one Hurler/Scheie patients. Primary clini- 
cal diagnosis was confirmed biochemically by the demonstration of increased excretion of urinary dermatan sulfate and heparan sulfate in the former, and IDUA activity in isolated leukocytes in the latter. Blood samples were collected, not only from the 10 patients, but also their respective parents. This study was approved by the Ethics Committee of the first Hospital of China Medical University, with full informed consent by the parents. The $\alpha$-Liduronidase enzyme activities in leucocytes of the patients were measured using the artificial substrate 4-methylumbelliferyl $\alpha$-L-iduronide (Sigma). The data of enrolled patients are summarized in Table 1.

Genomic DNA was extracted from venous blood by using a modified version of the ammonium acetate salting-out method. The IDUA gene was amplified from genomic DNA covering the entire IDUA coding region and exon - intron boundaries. Primer sequences, amplicon length and PCR reaction temperature are listed in Table 2. PCR was carried out in a mixture containing $200 \mathrm{ng}$ of DNA extracted from whole blood, $100 \mathrm{nM}$ of each outside primer, $10 \mathrm{mM}$ of Tris $-\mathrm{HCl}, \mathrm{pH} 8.3,1.5 \mathrm{mM}$ of $\mathrm{KCl}$, $2 \mathrm{mM}$ of $\mathrm{MgCl}_{2}, 100 \mu \mathrm{M}$ of each deoxyribonucleotide, and 1 unit of LA Taq DNA polymerase (Takara), in a total reaction volume of $50 \mu \mathrm{L}$. PCR conditions were as follows: denaturation at $95^{\circ} \mathrm{C}, 3 \mathrm{~min}$, followed by 35 cycles at $95^{\circ} \mathrm{C}$, $1 \mathrm{~min}, 62-68^{\circ} \mathrm{C}, 1 \mathrm{~min}, 72^{\circ} \mathrm{C}, 1 \mathrm{~min}$, and a final elongation at $72{ }^{\circ} \mathrm{C}, 7 \mathrm{~min}$. Each resulting PCR product was run on an $8 \%$ PAGE gel with a 100-bp marker for comparison. Restriction enzyme tests were designed to screen for p.W402X, p.Q70X (Clarke et al., 1994) and p.R89Q (Yamagishi et al., 1996) (Table 3). Negative, heterozygous and homozygous control samples were analyzed together with patient samples. All 14 exons of the IDUA gene were amplified and analyzed by means of single strand conformational polymorphism (SSCP) analysis. Electrophoresis was carried out overnight at $4{ }^{\circ} \mathrm{C}$. Those samples showing alterations were then sequenced. Mutations were confirmed by direct sequencing the reverse strand and restriction analysis.

The p.R363H mutation was introduced into wild-type IDUA cDNA which had been cloned into the pSP72 plasmid vector (Promega), by using the QuickChange sitedirected mutagenesis kit (Stratagene), according to manufacturer's instructions. Clones containing the mutagenized IDUA cDNA constructs were sequenced to ensure that no changes other than the desired mutation had been introduced. Chinese Hamster Ovary (CHO) cells were transfected with either the wild-type or a mutant cDNA construct using lipofectamine (Invitrogen). For each experiment, $2 \times 10^{5}$ cells were seeded $24 \mathrm{~h}$ prior to transfection. Each construct was transfected in triplicate using $0.4 \mu \mathrm{g}$ DNA and $5 \mu \mathrm{L}$ lipofectamine. Transfection complexes were removed after $6 \mathrm{~h}$ and replaced with full-growth medium. $24 \mathrm{~h}$ after transfection, efficiency was estimated by the number of cells expressing EGFP, as observed through an inverted fluorescent microscope. The cells were then washed twice with phosphate-buffered saline (PBS) and harvested in $1 \mathrm{~mL}$ of PBS, whereupon they were sonicated in $50 \mu \mathrm{L}$ of sterile water, centrifuged at $2000 \mathrm{rpm}$ for $10 \mathrm{~min}$, and then stored on ice. IDUA enzyme activity was measured with the artificial substrate 4-methylumbelliferyl alpha-L-iduronide. After incubation for $1 \mathrm{~h}$ at $37^{\circ} \mathrm{C}$, the reaction was terminated by way of $1.14 \mathrm{~mL}$ of $0.25 \mathrm{M}$ glycine $\mathrm{NaOH}$ buffer, $\mathrm{pH}$ 10.4. The fluorescence of released 4-methylumbelliferone was measured with an excitation wavelength of $365 \mathrm{~nm}$ and an emission wavelength of $450 \mathrm{~nm}$ (Young, 1992).

The common mutations, p.W402X and p.Q70X, associated with the Hurler phenotype, and p.R89Q, with the Scheie phenotype, were not found by restriction digestion of PCR products amplified from exon 2 and 9 of the IDUA gene, in any of the ten families.

Table 1 - Characteristics of the 10 Han Chinese MPS I patients.

\begin{tabular}{|c|c|c|c|c|}
\hline Patient number/sex & Phenotype & $\begin{array}{l}\text { Leukocyte IDUA activity } \\
\text { (nmol/h/mg protein) }\end{array}$ & Mutation identified & Major clinical manifestations \\
\hline $1 / \mathrm{m}$ & $\mathrm{H}$ & 0 & c. $1190-1 \mathrm{G}>\mathrm{A} /$ ? & $\begin{array}{l}\text { Severe mental retardation, corneal clouding, } \\
\text { skeletal deformities, and hepatosplenomegaly }\end{array}$ \\
\hline $2 / \mathrm{m}$ & $\mathrm{H}$ & 0 & c. $1190-1 \mathrm{G}>\mathrm{A} / \mathrm{c} .1190-1 \mathrm{G}>\mathrm{A}$ & Same as above \\
\hline $3 / \mathrm{m}$ & $\mathrm{H}$ & 0 & c. $1190-1 \mathrm{G}>\mathrm{A} / \mathrm{c} .792+1 \mathrm{G}>\mathrm{T}$ & Same as above \\
\hline $4 / \mathrm{m}$ & $\mathrm{H}$ & 0 & c. $792+1 \mathrm{G}>\mathrm{T} /$ c. $792+1 \mathrm{G}>\mathrm{T}$ & Same as above \\
\hline $5 / \mathrm{m}$ & $\mathrm{H}$ & 0 & c. $1190-1 \mathrm{G}>\mathrm{A} / \mathrm{c} .1190-1 \mathrm{G}>\mathrm{A}$ & Same as above \\
\hline $6 / \mathrm{m}$ & $\mathrm{H}$ & 0 & c. $792+1 \mathrm{G}>\mathrm{T} / ?$ & Same as above \\
\hline $7 / \mathrm{m}$ & $\mathrm{H}$ & 0 & c. $1190-1 \mathrm{G}>\mathrm{A} / ?$ & Same as above \\
\hline $8 / \mathrm{m}$ & $\mathrm{H}$ & 0 & c. $792+1 \mathrm{G}>\mathrm{T} / ?$ & Same as above \\
\hline $9 / \mathrm{m}$ & $\mathrm{H}$ & 0 & c. $1190-1 \mathrm{G}>\mathrm{A} /$ c. $792+1 \mathrm{G}>\mathrm{T}$ & Same as above \\
\hline $10 / \mathrm{F}$ & $\mathrm{H} / \mathrm{S}$ & 0.18 & c. $1190-1 \mathrm{G}>\mathrm{A} / \mathrm{p} \cdot \mathrm{R} 363 \mathrm{H}$ & $\begin{array}{l}\text { Hepatosplenomegaly, joint stiffness, corneal } \\
\text { clouding, and slightly mental delay }\end{array}$ \\
\hline
\end{tabular}


As shown in Table 1, the novel mutations found included one p.R363H missense mutation (c.1088G $>$ A) and two splice-site mutations (c.1190-1G > A and c.792+1G > $\mathrm{T})$. None of these were detected in 50 normal persons after direct sequencing of the PCR-amplified fragment containing intron 6 , exon 8 and intron 8 of the IDUA gene, respectively, thereby implying their not being polymorphisms, but in fact new mutations. The splice-site mutations c. $1190-1 \mathrm{G}>\mathrm{A}$ and c.792+1G $>$ T were further analyzed at the transcript level. The deletion of five exonic nucleotides caused by c. 1190-1G > A, resulted in the shift of the splice acceptor site of intron 8 (r.1189_1195del1190_1194), presumably leading to a frameshift, which started at the $397^{\text {th }}$ amino acid residue and ended at a premature stop codon, 110 amino acid residues downstream (p.D397GfsX110). The insertion of 17 intronic nucleotides caused by c. $792+1 \mathrm{G}>\mathrm{T}$, resulted in a shift of the intron 6 splicedonor site (r.792_793ins792+1_792+17), presumably leading to a frameshift, which started at the $265^{\text {th }}$ amino acid residue and ended at a premature stop codon, 58 amino acid residues downstream (p.G265LfsX 58 ). Notably, 45\% (nine out of 20 ) and $30 \%$ (six out of 20 ) of the mutant alleles in

Table 2 - PCR primer sequences, amplicon length and PCR reaction temperature.

\begin{tabular}{|c|c|c|c|}
\hline Exon & Primer sequence & Amplicon length (bp) & Annealing temperature $\left({ }^{\circ} \mathrm{C}\right)$ \\
\hline 1 & $\begin{array}{l}\text { F: 5'-ACCCAACCCCTCCCAC-3'; } \\
\text { R: 5'-GCTCCGGTCTCTGAAGCT-3' }\end{array}$ & 398 & 64 \\
\hline 2 & $\begin{array}{l}\text { F: 5'-GGCTTGAACGTGTGTGTCAGCCGC-3'; } \\
\text { R: 5'-GTAAGGGGCTCTGGGACGCCCAGA-3' }\end{array}$ & 258 & 65 \\
\hline 3 & $\begin{array}{l}\text { F: 5'-AGGTCCTGCCTGGCTCCTGA-3'; } \\
\text { R: 5'-GGCTGGGAGCAGAGCCCACA-3' }\end{array}$ & 450 & 66 \\
\hline 4 & $\begin{array}{l}\text { F: 5'-ACCCTCTCCCTCACCCAG-3'; } \\
\text { R: 5'-GCGTGATAGGGGTGCAAC-3' }\end{array}$ & 312 & 64 \\
\hline 5 & $\begin{array}{l}\text { F: 5'-CATCACCTTGCACCCTCC-3'; } \\
\text { R: 5'-CGTCTACACCTGCCCTGG-3' }\end{array}$ & 273 & 64 \\
\hline 6 & $\begin{array}{l}\text { F: 5'-CCGCTCATCCCCAGGGCAGGTGTA-3'; } \\
\text { R: 5'-ACAGCGGCTGAGGGCGCAGAACAC-3' }\end{array}$ & 301 & 66 \\
\hline 7 & $\begin{array}{l}\text { F: 5'-CGCGCTGACCCTGGTGGTGGTGA-3'; } \\
\text { R: 5'-GCCGGGGGGCGCGCAGGGCGTT-3' }\end{array}$ & 254 & 68 \\
\hline 8 & $\begin{array}{l}\text { F: 5'-TTCCTCCCGAGACGGGACAGGCGA-3'; } \\
\text { R: 5'-TTCCTCCCGAGACGGGACAGGCGA-3' }\end{array}$ & 350 & 67 \\
\hline 9 & $\begin{array}{l}\text { F: 5'- TGGGGACTCCTTCACCAAGGGGAG-3'; } \\
\text { R: 5'-CAGAGCCCCAGCGGGGCCAGAGAC-3' }\end{array}$ & 371 & 68 \\
\hline 10 & $\begin{array}{l}\text { F: 5'-GGTGACCCTGCGGCTG-3'; } \\
\text { R: 5'-TCCTCAGGGTTCTCCAGG-3' }\end{array}$ & 421 & 61 \\
\hline 11 & $\begin{array}{l}\text { F: 5'-GTGTGGGTGGGAGGTGGAGCGGTG-3'; } \\
\text { R: 5'-AGGGAAGGCCTGTGATGGCGTCGG-3' }\end{array}$ & 301 & 65 \\
\hline 12 & $\begin{array}{l}\text { F: 5'-GCAGGCAAGTGGCAGTCCC-3'; } \\
\text { R: 5'-GGCAAGTGGCCCGAGTGAC-3' }\end{array}$ & 253 & 68 \\
\hline 13 & $\begin{array}{l}\text { F: 5'-GGGGCTTGAGGGAATGAG-3'; } \\
\text { R: 5'-CCTGACCCCAGGCTTCTC-3' }\end{array}$ & 300 & 62 \\
\hline 14 & $\begin{array}{l}\text { F: 5'-CAGGGCAGTACTGGGTGG-3'; } \\
\text { R: 5'-TATATTGCAAAGGGGGTGATG-3' }\end{array}$ & 331 & 62 \\
\hline
\end{tabular}

F: forward primer; R: reverse primer.

Table 3 - Restriction enzyme tests for 3 known mutations in MPS I patients.

\begin{tabular}{lllll}
\hline Phenotype & Mutation & Primers & Restriction enzyme & Fragment sizes (bp) \\
\hline \multirow{2}{*}{ Hurler } & p.Q70X (exon 2) & F: 5'-CGCTGCCAGCCATGCTGAGGCTCG-3'; & -Sau96I & $\mathrm{N}: 310+99+57+5$ \\
& & R: 5'-ACACAGGGATGCTCACGGGTGACC-3' & & M:310+156+5 \\
Hurler & p.W402X (exon 9) & F: 5'-TGGCGGGGCCTGGGGACTCCTTCACCTA-3'; & + BfaI & $\mathrm{N}: 26+248$ \\
& & R: 5'-GCGGGTGTCGTCGCTCGCGTAGAT-3' & & M:26+110+138 \\
Scheie & p.R89Q (exon 2) & F: 5'-CGCTGCCAGCCATGCTGAGGCTCG-3'; & - MspI & N:312+159 \\
& & R: 5'-ACACAGGGATGCTCACGGGTGACC-3' & & M:471 \\
\hline
\end{tabular}

All PCR reactions were carried out with 200 ng genomic DNA.

( $\mathrm{N}$ normal; M mutant; +/- gain or loss of restriction enzyme site respectively). 
the Chinese MPS I families were c.1190-1G > A and c. $792+1 \mathrm{G}>\mathrm{T}$, respectively. 4 previously reported polymorphisms, viz., p.R105Q, p.L118, p.A314 and p.A361T, were found. All sequence changes were confirmed by restriction enzyme testing on a second PCR product.

A mutant construct was generated, in order to determine whether the novel missense mutation p. $\mathrm{R} 363 \mathrm{H}$ was disease-causing. $\mathrm{CHO}$ cells were transfected with either the wild-type or a mutant construct, using lipofectamine. The mutant construct reduced IDUA enzyme activity to $2.1 \mathrm{nmol} / \mathrm{h} / \mathrm{mg}$ protein, whereas enzyme activity in $\mathrm{CHO}$ cells transfected with the wild-type was $90.8 \mathrm{nmol} / \mathrm{h} / \mathrm{mg}$ protein. p.R363H expression showed retention of $2.3 \%$ IDUA activity, thereby implying that this novel mutation is, in fact, pathogenic.

MPS I is caused by mutations of the IDUA gene, these including missense and nonsense, splice-site, and insertion or deletion mutations. The Han Chinese ethnic group is the most populous in the world, whereby the significance of specifically identifying the molecular genetical background of MPS I patients in this assemblage. $80 \%$ (16 out of 20) of the alleles in the 10 Han Chinese MPS I families studied, were identified. The four unidentified ones are probably situated further within the intronic or promoter regions, not included in this study. The method employed could also be in arrear. The results of screening for known mutations showed that p.W402X and p.Q70X, the most frequent mutations in European patients, did not appear in Han Chinese MPS I patients. Moreover, p.R89Q, the most common mutant IDUA allele in Japanese MPS I patients, and other mutations, such as p.Y64X, p.Q310X, p.T366P (Bach et al., 1993), p.P228Q, p.S534X, p.Y618X, c.193delT (Lee et al., 2004) and p.E299X (Ketudat Cairns et al., 2005) in Asian MPS I patients, were also not found in the Han Chinese.

Table 4 - Summary of IDUA mutations in Chinese MPS-I patients.

\begin{tabular}{|c|c|c|c|c|c|}
\hline Mutation & Codon change & Location & Associated phenotype & Mutation type & Reference \\
\hline c. $46 \_57 \mathrm{del}$ & - & Exon 1 & Hurler & Deletion mutation & Lee-Chen et al. 2002 \\
\hline p.Q60X & CAG-TAG & Exon 2 & Scheie & Missense mutation & Dou et al. 2007 \\
\hline p.A79V & GCC-GTC & Exon 2 & Hurler/ Scheie & Missense mutation & Lee-Chen et al. 2002 \\
\hline c. $388-3 \mathrm{C}>\mathrm{G}$ & - & Intron 2 & Hurler & Splice mutation & Teng et al. 2000 \\
\hline p.D203N & GAT-AAT & Exon 6 & Scheie & Missense mutation & Dou et al. 2007 \\
\hline c. $792+1 \mathrm{G}>\mathrm{T}^{*}$ & - & Intron 6 & Hurler & Splice mutation & This study \\
\hline p.Y343X & TAC-TAG & Exon 8 & Hurler/ Scheie & Nonsense mutation & Lee-Chen et al. 1997 \\
\hline p.L346R & CTG-CGG & Exon 8 & Hurler/ Scheie & Missense mutation & Teng et al. 2000 \\
\hline p. $\mathrm{R} 363 \mathrm{H}^{*}$ & CGC-CAC & Exon 8 & Hurler/ Scheie & Missense mutation & This study \\
\hline p.T364M & ACG-ATG & Exon 8 & Hurler/ Scheie & Missense mutation & Lee-Chen et al. 1997 \\
\hline c. $1190-1 \mathrm{G}>\mathrm{A}^{*}$ & - & Intron 8 & Hurler & Splice mutation & This study \\
\hline p.Q584X & CAG-TAG & Exon 13 & Hurler & Nonsense mutation & Lee-Chen et al. 2002 \\
\hline p.R619G & CGA-GGA & Exon 14 & Hurler/ Scheie & Missense mutation & Lee-Chen et al. 1999 \\
\hline
\end{tabular}

*Unique mutations in Han Chinese MPS I families.
The two missense mutations, p.Q60X and p.D203N, were previously described in a Chinese MPS IS patient (Dou et al., 2007), and p.Q60X alone as a rare IDUA allele in MPS I patients from the UK (Beesley et al., 2001), although p.D203N has, as yet, not been identified in patients elsewhere. Furthermore, eight rare IDUA alleles were found in MPS I patients from Chinese Taipei. These included two previously reported missense mutations, p.Y343X (Voskoboeva et al., 1998) and p.A79V (Yogalingam et al., 2004), as well as four missense mutations, p.T364M (Lee-Chen and Wang, 1997), p.R619G (LeeChen et al., 1999), and p.L346R and p.Q584X (Lee-Chen et al., 2002), one splice-site mutation c.388-3C > G (Teng et al., 2000), and one deletion mutation c.46_57del unique for China. IDUA gene mutations identified in Chinese MPS I patients are listed in Table 4. A screening for the known mutation in 35 Chinese MPS I patients revealed that p.W402X, p.Q70X, p.P533R and p.R89Q were not present among 70 alleles of the IDUA gene (Yu et al., 2001). Unfortunately, there is a lack of pertinent information regarding the patients' ethnic group in the literature.

Thus, it is shown that Chinese MPS I patients are characterized with a unique set of IDUA gene mutations, not only different from those encountered among Europeans and Americans, but also apparently diverse from those present in other Asian populations. Furthermore, p.W402X and p.Q70X were absent from Asian MPS I patients, thereby emphasizing their uniqueness.

Genotype-phenotype correlations have been reported, as, for example, the p.W402X and p.Q70X Hurler mutations. These have been shown to be particularly prevalent (72\%) in north European populations, with a high proportion of severely affected patients. Nevertheless, several mutations, such as p.P533R, seemed to correlate to different phenotypes in Italian MPS-I patients (Gatti et al., 1997), 
while a patient homozygous for $\mathrm{p} . \mathrm{W} 402 \mathrm{X}$, and presenting the less severe Scheie phenotype, has also been described (Pereira et al., 2008). On the other hand, missense mutations distributed along the entire length of the gene may be associated with severe phenotypes (Vazna et al., 2009).

Most of the patients were severely affected in the cases under study. The homozygote for both c.1190-1G $>$ A and c. $792+1 \mathrm{G}>\mathrm{T}$, as well as the heterozygote for c. $1190-1 \mathrm{G}>\mathrm{A}$ and c. $792+1 \mathrm{G}>\mathrm{T}$, exhibited the Hurler syndrome. Thus, these two mutations might be associated with a severe phenotype, consistent with Terlato's idea that most splice-site mutations result in a severe phenotype, unless in combination with a less severe missense mutation (Terlato and Cox, 2003). c.1190-1G > A and c. $792+1 \mathrm{G}>\mathrm{T}$ were further analyzed at the transcript level, whereupon they proved to be acceptor and donor splice-site mutations, respectively, thus presumably leading to a frameshift. Moreover, these mutations were absent from 50 unrelated controls, thereby implying their probable pathogenicity.

The only Hurler/Scheie syndrome patient was the heterozygote for c.1190-1G > A/p.R363H. The novel p.R363H missense mutation was due to a $\mathrm{G}$ to $\mathrm{C}$ transversion in codon 363 , thereby resulting in the substitution of a histidine by an arginine residue. It is generally accepted that less severe $\mathrm{H} / \mathrm{S}$ syndrome patients are associated with a milder allele that produces some residual enzyme activity. Thus, as c.1190-1G > A homozygotes possess a severe phenotype, p.R363H can be most likely associated with a mild to intermediate one. p.R363H expression showed retention of $2.3 \%$ IDUA activity, thus in accordance with that predicted. The analogous mutation p.R363C (substitution of a cysteine by an arginine residue) has been previously reported (Yogalingam et al., 2004), although no IDUA activity was detected in CHO p.R363C cells. This is possibly due to those conformational changes in IDUA taking place on the basic amino acid, being replaced by neutral cysteine, thereby leading to a loss in enzyme activity.

Identification of IDUA mutations in the 10 Chinese MPS I families permits accurate carrier detection and genetic counseling of at-risk relatives, and should facilitate molecular prenatal diagnosis in China. Moreover, thereby genetic clues for the diagnosis and treatment of overseas Chinese MPS I patients might be provided, due to their unique IDUA gene mutations. The available treatments for MPS I patients include hematopoietic stem cell transplants and enzyme replacement therapy. Genotype studies assist in the prediction of disease severity in MPS I patients, and could, together with the age of the patient at diagnosis, aid in taking a decision regarding treatment measures. Recently, a further more efficacious treatment for MPS I Hurler patients-hematopoietic stem-cell gene therapy, based on lentiviral vectors and the success with mouse models, completely corrects disease manifestations (Visigalli et al., 2010). Our data provide additional evidence for the future development of clinically testing this same therapy.

\section{Acknowledgments}

This work was supported by a grant from the National Nature Science Foundation of China (grant 39570745).

\section{References}

Bach G, Moskowitz SM, Tieu PT, Matynia A and Neufeld EF (1993) Molecular analysis of Hurler syndrome in Druze and Muslim Arab patients in Israel: Multiple allelic mutations of the IDUA gene in a small geographic area. Am J Hum Genet 53:330-338.

Beesley CE, Meaney CA, Greenland G, Adams V, Vellodi A, Young EP and Winchester BG (2001) Mutational analysis of 85 mucopolysaccharidosis type I families: Frequency of known mutations, identification of 17 novel mutations and in vitro expression of missense mutations. Hum Genet 109:503-511.

Bunge S, Kleijer WJ, Steglich C, Beck M, Zuther C, Morris CP, Schwinger E, Hopwood JJ, Scott HS and Gal A (1994) Mucopolysaccharidosis type I: Identification of 8 novel mutations and determination of the frequency of the two common alpha-L-iduronidase mutations (W402X and Q70X) among European patients. Hum Mol Genet 3:861-866.

Clarke LA, Nelson PV, Warrington CL, Morris CP, Hopwood JJ and Scott HS (1994) Mutation analysis of 19 North American mucopolysaccharidosis type I patients: Identification of two additional frequent mutations. Hum Mutat 3:275-282.

Dou W, Peng C, Zheng JK and Gu XF (2007) A novel mutation of the alpha-L-iduronidase gene in a patient with mucopolysaccharidosis type I. Zhonghua Yi Xue Yi Chuan Xue Za Zhi 24:136-139.

Gatti R, DiNatale P, Villani GR, Filocamo M, Muller V, Guo XH, Nelson PV, Scott HS and Hopwood JJ (1997) Mutations among Italian mucopolysaccharidosis type I patients. J Inherit Metab Dis 20:803-806.

Hopwood JJ and Morris CP (1990) The mucopolysaccharidoses. Diagnosis, molecular genetics and treatment. Mol Biol Med 7:381-404.

Ketudat Cairns JR, Keeratichamroen S, Sukcharoen S, Champattanachai V, Ngiwsara L, Lirdprapamongkol K, Liammongkolkul S, Srisomsap C, Surarit R, Wasant P, et al. (2005) The molecular basis of mucopolysaccharidosis type I in two Thai patients. Southeast Asian J Trop Med Public Health 36:1308-1312.

Lee IJ, Hwang SH, Jeon BH, Song SM, Kim JS, Paik KH, Kwon EK and Jin DK (2004) Mutational analysis of the alphaL-iduronidase gene in 10 unrelated Korean type I mucopolysaccharidosis patients: Identification of four novel mutations. Clin Genet 66:575-576.

Lee-Chen GJ and Wang TR (1997) Mucopolysaccharidosis type I: Identification of novel mutations that cause Hurler/Scheie syndrome in Chinese families. J Med Genet 34:939-941.

Lee-Chen GJ, Lin SP, Tang YF and Chin YW (1999) Mucopolysaccharidosis type I: Characterization of novel mutations affecting alpha-L-iduronidase activity. Clin Genet 56:66-70. 
Lee-Chen GJ, Lin SP, Chen IS, Chang JH, Yang CW and Chin YW (2002) Mucopolysaccharidosis type I: Identification and characterization of mutations affecting alpha-L-iduronidase activity. J Formos Med Assoc 101:425-428.

Pereira VG, Martins AM, Micheletti C and D'Almeida V (2008) Mutational and oxidative stress analysis in patients with mucopolysaccharidosis type I undergoing enzyme replacement therapy. Clin Chim Acta 387:75-79.

Schuchman EH and Desnick RJ (1988) Mucopolysaccharidosis type I subtypes. Presence of immunologically cross-reactive material and in vitro enhancement of the residual alphaL-iduronidase activities. J Clin Invest 81:98-105.

Teng YN, Wang TR, Hwu WL, Lin SP and Lee-Chen GJ (2000) Identification and characterization of $-3 \mathrm{c}-\mathrm{g}$ acceptor splice site mutation in human alpha-L-iduronidase associated with mucopolysaccharidosis type IH/S. Clin Genet 57:131-136.

Terlato NJ and Cox GF (2003) Can mucopolysaccharidosis type I disease severity be predicted based on a patient's genotype? A comprehensive review of the literature. Genet Med 5:286-594.

Vazna A, Beesley C, Berna L, Stolnaja L, Myskova H, Bouckova M, Vlaskova H, Poupetova H, Zeman J, Magner M, et al. (2009) Mucopolysaccharidosis type I in 21Czech and Slovak patients: Mutation analysis suggests a functional importance of C-terminus of the IDUA protein. Am J Med Genet Part A 149A:965-974.

Visigalli I, Delai S, Politi LS, Di Domenico C, Cerri F, Mrak E, D'Isa R, Ungaro D, Stok M, Sanvito F, et al. (2010) Gene therapy augments the efficacy of hematopoietic cell trans- plantation and fully corrects Mucopolysaccharidosis type I phenotype in the mouse model. Blood 116:5130-5139.

Voskoboeva EY, Krasnopolskaya XD, Mirenburg TV, Weber B and Hopwood JJ (1998) Molecular genetics of mucopolysaccharidosis type I: Mutation analysis among the patients of the former Soviet Union. Mol Genet Metab 65:174-180.

Yamagishi A, Tomatsu S, Fukuda S, Uchiyama A, Shimozawa N, Suzuki Y, Kondo N, Sukegawa K and Orii T (1996) Mucopolysaccharidosis type I: Identification of common mutations that cause Hurler and Scheie syndromes in Japanese populations. Hum Mutat 7:23-29.

Yogalingam G, Guo XH, Muller VJ, Brooks DA, Clements PR, Kakkis ED and Hopwood JJ (2004) Identification and molecular characterization of alpha-L-iduronidase mutations present in mucopolysaccharidosis type I patients undergoing enzyme replacement therapy. Hum Mutat 24:199-207.

Young EP (1992) Prenatal diagnosis of Hurler disease by analysis of alpha-iduronidase in chorionic villi. J Inherit Metab Dis 15:224-230

Yu H, Zeng R and Lin Q (2001) Mutations analysis of IDUA gene in Chinese mucopolysacchridosis type 1 patients. Acad J SUMS 22:439-442.

\section{Internet Resources}

Human Gene Mutation Database, http://www.hgmd.org.

Associate Editor: Paulo A. Otto

License information: This is an open-access article distributed under the terms of the Creative Commons Attribution License, which permits unrestricted use, distribution, and reproduction in any medium, provided the original work is properly cited. 